\title{
Communication as a Crucial Element for Enterprise Architecture Management in Virtual Organization
}

\author{
Taivo Kangilaski \\ Tallinn University of Technology, Department of Computer Control, Ehitajate tee 5, \\ 19086 Tallinn, Estonia \\ Taivo.Kangilaski@dcc.ttu.ee
}

\begin{abstract}
New business condition and current economical situation are forcing companies to rethink their way of operating. The rapidity of managing changes has become increasingly important. To be more competitive, companies are forming Virtual Organizations (VO) where short-term spontaneous collaboration activities are rather common. Such interoperability leads to increasing organizational architectural complexity. As the VO interoperability availability depends on quality of companies Enterprise Architecture approach belonging to ecosystem, the current article propose focus points for architecture management in VO.
\end{abstract}

Keywords: Enterprise Architecture, Virtual Organization, Communication.

\section{Introduction}

Nowadays economical situation influences companies greatly - competitive pressures, corporate mergers, acquisitions, shortened product development times and production cycles, shifting supplier relationships, and various customer demands are forcing companies to adapt to the changing market conditions. Companies with better financial and market position are forming new ecosystems in order to be more competitive and flexible.

Building ecosystems means that necessary companies are initially recruited among the partners and are employed as subcontractors for the necessary tasks by the Focal Player in his role as the general project manager. In case the needed competencies are not represented in the partner network or they are not of a sufficiently high quality, the external companies will be asked to participate. Such a co-operation could be modelled through the Virtual Organization (VO) approach [1].

At the same time, it is obvious that the alliance partners have different business processes, ontologies, organizational structures, technologies, management principles etc. As the entire setup of the VO may change according to the marketplace [2], the VOs are temporary organizations and have ability to react quickly regarding to membership, structure, objectives, etc. It means increasing complexity of business as well as IT environment, which is often disabling factor for flexible enterprise architecture management.

P. Bernus, G. Doumeingts, and M. Fox (Eds.): EAI2N 2010, IFIP AICT 326, pp. 66-77, 2010.

(C) IFIP International Federation for Information Processing 2010 
The current article focuses on the importance of communication of Enterprise Architecture (EA) in $\mathrm{VO}$ as one of the most important enabler to minimize interoperability issues both between VO Collaborators (VOC) and with external contractors.

The article is built up as following: in the next section, the concept of VO is analyzed to show the key components, which should be focused on. In the third section the EA as a discipline is briefly introduced. The fourth section proposes approach, how to handle EA complexity in VO. Then the ontology conformation processes inside VO are being analyzed. Based on these, the approach how to handle EA communication in $\mathrm{VO}$ is proposed.

\section{Virtual Organization}

In theory, all companies should perform their work exceptionally well. When they succeed in the short term, they should also, to the fullest extent possible, follow their goals and strategies to pursue longer-term opportunities and threats. Such behavior requires management vision, considerable resources, infrastructure, and dedicated personnel. It is often anticipated that all employees will act effectively always, make sense of challenges, find the best approaches to handle situations, anticipate outcomes, inform all stakeholders who are concerned, etc. But the main factor here, what needs to be emphasized, is that enterprise has a common ownership. VO, contrarily has temporary nature and lack of common ownership.

Field of VO has covered with many research projects. The main focuses have been on the characteristics of a VO (e.g. purpose, time and spatial dispersion, modularity, heterogeneity, interdependence, configuration, boundaries, knowledge management, uncertainty, trust, culture) [3]-[17], the VO lifecycle management (e.g. creation, operation, dissolution) [18][19], the software integration issues (e.g. integration middleware, Service Oriented Architecture (SOA), Enterprise Service Bus, Business Process Management (BPM)) [20]-[23], integral management of information [24], but EA as a discipline for VO is weakly covered.

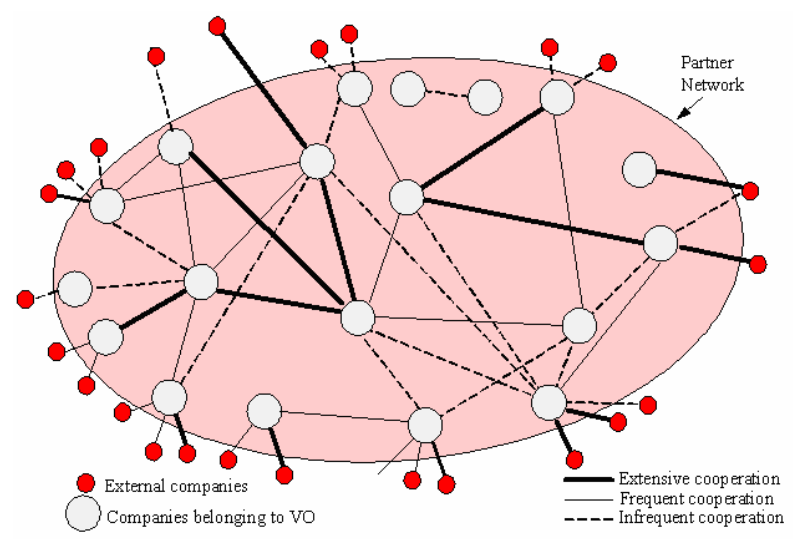

Fig. 1. Partner Network and its partners' intensity of interoperability 
Table 1. Communication intensity properties

\begin{tabular}{|c|c|c|c|c|}
\hline Property & $\begin{array}{l}\text { Extensive } \\
\text { communication }\end{array}$ & $\begin{array}{l}\text { Frequent } \\
\text { communication }\end{array}$ & $\begin{array}{l}\text { Infrequent } \\
\text { communication }\end{array}$ & $\begin{array}{l}\text { Passive } \\
\text { communication }\end{array}$ \\
\hline Culture & Conformed & $\begin{array}{l}\text { Principles are } \\
\text { agreed }\end{array}$ & $\begin{array}{l}\text { Different } \\
\text { organizational } \\
\text { culture, problems } \\
\text { with semantics }\end{array}$ & $\begin{array}{l}\text { Different } \\
\text { organizational } \\
\text { culture, -ontology }\end{array}$ \\
\hline Processes & $\begin{array}{l}\text { Selection of } \\
\text { common } \\
\text { approach }\end{array}$ & $\begin{array}{l}\text { Many different } \\
\text { tactics are used, but } \\
\text { best practices are } \\
\text { in place }\end{array}$ & $\begin{array}{l}\text { People are } \\
\text { dependent } \\
\text { without any } \\
\text { formal practices } \\
\text { or plans }\end{array}$ & $\begin{array}{l}\text { Cooperation is } \\
\text { missing }\end{array}$ \\
\hline Human factor & $\begin{array}{l}\text { Permanent } \\
\text { networking } \\
\text { staff }\end{array}$ & $\begin{array}{l}\text { Established } \\
\text { networking; new } \\
\text { persons are } \\
\text { involved }\end{array}$ & $\begin{array}{l}\text { Exploring } \\
\text { collaboration } \\
\text { possibilities }\end{array}$ & $\begin{array}{l}\text { Not direct } \\
\text { collaboration. } \\
\text { Information } \\
\text { through the Web }\end{array}$ \\
\hline Risk taking & $\begin{array}{l}\text { Low, as people } \\
\text { know each } \\
\text { other }\end{array}$ & Medium & Medium/High & $\begin{array}{l}\text { N/A - only } \\
\text { needed/minimal } \\
\text { information is } \\
\text { published }\end{array}$ \\
\hline $\begin{array}{l}\text { Knowledge } \\
\text { sharing }\end{array}$ & High & High & Medium & $\begin{array}{l}\text { Minimum - limited } \\
\text { access to } \\
\text { information }\end{array}$ \\
\hline ICT support & $\begin{array}{l}\text { High - most } \\
\text { business } \\
\text { processes are } \\
\text { supported by } \\
\text { ICT }\end{array}$ & $\begin{array}{l}\text { Medium - different } \\
\text { initiatives to } \\
\text { support processes } \\
\text { by ICT }\end{array}$ & $\begin{array}{l}\text { Low - core } \\
\text { processes are } \\
\text { partly supported } \\
\text { by ICT }\end{array}$ & $\begin{array}{l}\text { Very low - only } \\
\text { VO basic ICT } \\
\text { solutions needed } \\
\text { for VO are } \\
\text { available }\end{array}$ \\
\hline Trust & $\begin{array}{l}\text { High }- \text { a lot of } \\
\text { good references } \\
\text { and personal } \\
\text { experiences }\end{array}$ & $\begin{array}{l}\text { Medium - previous } \\
\text { personal } \\
\text { experience is } \\
\text { small. Good } \\
\text { references about } \\
\text { the VOC are } \\
\text { available }\end{array}$ & $\begin{array}{l}\text { Low - personal } \\
\text { experience is } \\
\text { missing. The } \\
\text { trust must be } \\
\text { developed, others } \\
\text { VOC references } \\
\text { are needed }\end{array}$ & $\begin{array}{l}\text { Low - information } \\
\text { is accessible only } \\
\text { when there is an } \\
\text { other VOC } \\
\text { reference is } \\
\text { available }\end{array}$ \\
\hline
\end{tabular}

Through the communication intensity analyzes, the other aspects of VOCs communication may be identified - working culture, process maturity, human factor, risk taking, knowledge sharing, ICT support and trust (Table 1.). Only these characteristics are elected as the focal characteristics, which will influence companies' cooperation because these are the most important factors for further VO and Partner Network EA governance.

Extensive communication is cooperation between VOCs, where amount of work covered with contracts is huge, trust between organizations is high, employees know each other, semantics is conformed and processes are combined and optimized with help of ICT solutions. Typically, VOC with extensive communications have 
long-term frame agreements and there are several business projects performing simultaneously. It can be said that these cooperation partners ontologies are conforming.

Frequent communication is cooperation between VOCs, where amount of work covered with contracts is considerable. These companies have earlier made successful cooperation, and now these companies have slightly different semantics, different understandings about business processes and there is a weaker social cooperation between VOC's employees. The cooperation relies largely on ICT solutions, but there is no "single work-desk on computer" for employees to support business processes. Typically VOCs with frequent communications are entering to the extensive communication when cooperation is successful, otherwise it returns to the infrequent communication until companies' organizational maturity will grow. In this type of communication, VOCs have also long term frame agreements with multiple simultaneous projects.

Infrequent communication is cooperation between VOCs, where amount of work covered with contracts is small. There may be several simultaneous projects, but all of them are covered with separate contracts. The processes, working principles, semantics, and cultures are different and will affect the cooperation also aggravating the speed to start a new cooperation project. From ICT side, the major business processes are partly covered by ICT applications to accelerate information exchange and analyzes capabilities. As the companies belong to the same VO, there may be recommendations with testimonial from others VOCs, which will facilitate the start of effective cooperation comparing with that with companies from outside VO.

Passive communication is mainly a one-way communication. It means that VOC will publish information needed for others VOCs to analyze the efficiency of value chain they belong to. Mostly that information contains VOC's most critical information for effective cooperation with partners and which refer to:

- available machinery/inventories and their location;

- available competences, skills, skills locations;

- ongoing and further known projects.

This information is accessible only companies belonging to VO. There is always a passive communication oriented to all companies to find cooperation partners if needed. Mostly, passive communication is forwarded through VOC Internet web pages to the Partner Network companies and with restricted access to external companies.

\section{Enterprise Architecture}

Concept of Enterprise Architecture (EA) management is well known. It is widely analyzed that well-documented and well-understood EA enables the organization to respond quickly to changes in the environment in which the organization operates. EA serves as a ready reference that enables the organization to assess the impact of the changes on each of the EA components. 
According to the ToGAF ver.9 [25], it is reasonable to define Enterprise and Architecture separately. Enterprise is the highest level of description of an organization and typically covers all missions and functions. Architecture is the structure of components, their interrelationships, and the principles and guidelines governing their design and evolution over time. These definitions together will give precise meaning of EA.

In addition to ToGAF, there are many well known EA frameworks - U.S. Department of Defense Architecture Framework (DoDAF), British Ministry of Defence Architectural Framework (MoDAF), U.S. Federal Enterprise Architecture framework (FEA), Gartner Enterprise Architecture Framework, Computer Integrated Manufacturing Open System Architecture modelling framework (CIMOSA), Purdue Enterprise Reference Architecture (PERA), Treasury Enterprise Architecture Framework (TEAF), TeleManagement (TM) Forums eTOM/New Generation Operations Systems and Software (NGOSS), Center of Excellence of Enterprise Architecture (CEISAR) approach, Generalised Enterprise Reference Architecture and Methodology (GERAM), Supply Chain Operations Reference model (SCOR), ISO/IEC 42010:2007, Reference Model of Open Distributed Processing (RM-ODP), Spewak EA Planning Methodology, Pragmatic enterprise architecture Framework (PeaF).

There are also well known Zachman Framework ${ }^{\mathrm{TM}}$ and IDS Scheer ARIS framework but these are ontologies without implementation processes.

Most of these architecture frameworks have a common property - the enterprise has a common ownership. VO contrarily has a lack of common ownership, which also demands different interpretation of these frameworks.

In broadly, EA in context of VO can be documented in five layers [24] Infrastructure layer, data layer, application layer, business process layer, and key performance indicators (KPI) layer (Fig.2.).

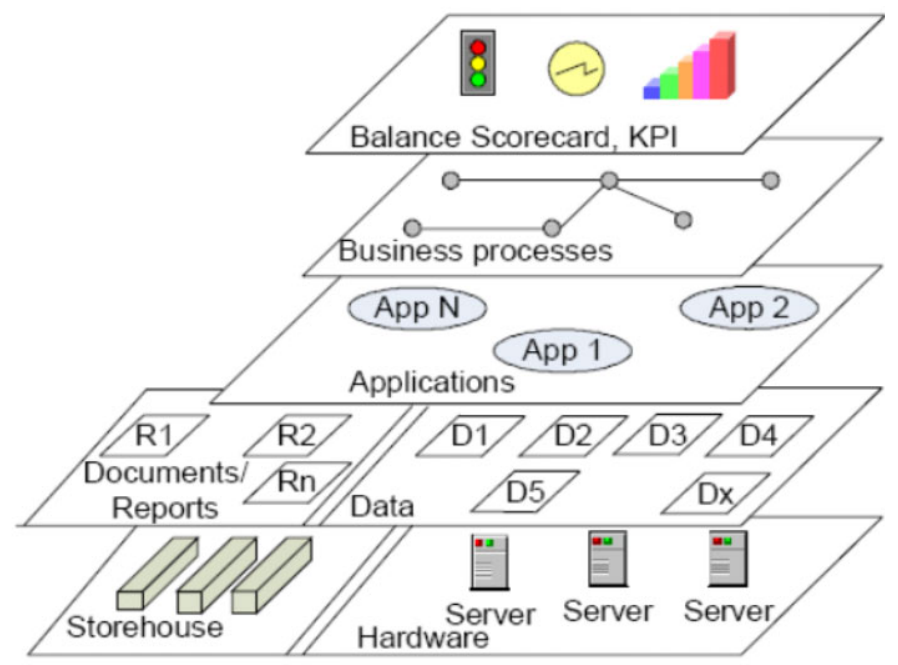

Fig. 2. Documentation layers [24] 
The infrastructure layer refers to the network connectivity, hardware upon which the software runs, network routers, operating systems, and other technologies that facilitate the communication among the distributed software components and support the execution environment of the software. It is crucial for the enterprise to record its paper documents'/reports' physical locations (e.g. in storehouses).

The data layer refers to how the data is structured, stored, and handled. It includes the specification of databases, the logical and physical database design, the allocation of data to servers, the strategy for data replication and archival, as well as to the strategy and design of the data warehouse. In that level, also, all paper documents/reports produced by business processes should be described. It is important to analyze business situation to cover the new areas for the new or improved software solutions.

The application layer describes several business services (incl. web services), applications, their functionalities and Service Level Agreements. For a certain product, the application layer is the documentation about the product's software architecture. This layer provides also a set of guidelines about how the various software solutions should be consistently constructed across the VO.

The business process layer describes the business processes, their constraints, demands and goals. That documentation layer expected to give an overview of the applications being used to support the certain business processes.

The application documentation should be complementary to the business process documentation.

The KPI layer documentation describes the key business strategies, organization and goals that are closely related to business processes. This is very important in context of VOC, as it must adapt its operations according to the VO's changing environment. The goal of KPI-s is to direct the organizational behavior and its focus areas to the wanted directions.

All these layers together provide not only a vision and the consistent principles applied on all the layers, but also the addresses objectives such as security, common semantic, flexibility, make the versus buy decisions, reuse and domains where to invest.

All these documentation dimensions are very important for architecture management, which means for EA governance it is needed to handled these as:

1. EA level - defines overall management principles which determines all architecture principles and main architecture contracts for companies;

2. Domain level - specifies rules for certain business domain, focuses in more detail to certain business domain semantics, business processes, KPI-s, applications, and infrastructure;

3. Application governance level - handles EA in the lowest level, focuses on data model, application integration, business processes which are implemented into the applications and all related documentation.

To conclude, each of these levels has different generalization of these EA documentation levels described above. 


\section{Ontology Overlapping in VO}

It is well known from theory of collective intelligence, that during the cooperation, participants in the communication will influence each other [26] in a way they will modify their behavior based upon the assessment of their roles and outcomes.

In context of VO, it means that based on VOC-s interoperability connection intensity, the mutual influences will influence VOC ontology. The influence depends, in addition, on VOC's organizational maturity, size, company geographical distribution, and on the experiences in the specific business sphere.

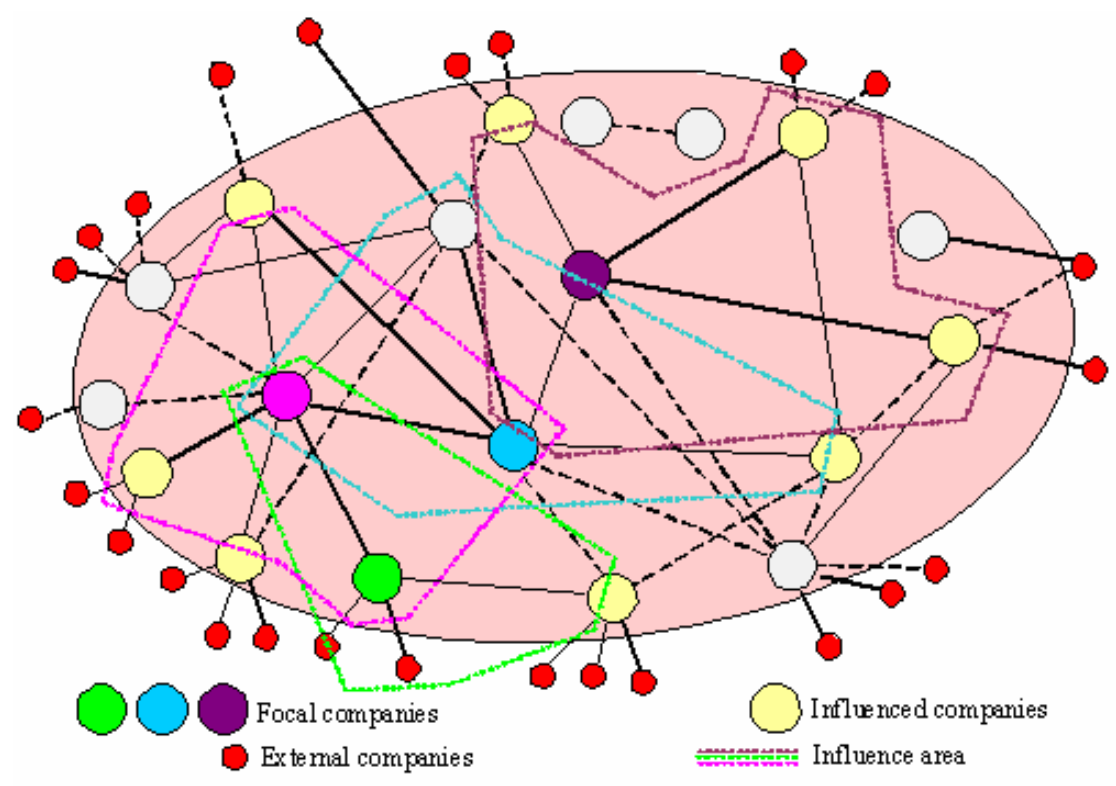

Fig. 3. VO focal players influence areas

As already described, depending on size of VO, there is usually more than one focal player, which dominates in VO value chain. These focal players have reputation, economical power and a higher or equal maturity level comparing to Partner Network, which means that focal players will influence their own partner network with which they have business relationship (first front partners). The extent of influence will depend on the intensity of the interoperability connection (Fig.3.).

As the first front partners have their own contract partners (the second front partners), it means that the focal player will influence the second front partners as well even though the influence is much weaker.

Consequently there are overlapping areas of ontology creating semantic synchronization / transformation (Fig.4.). The area bounds depend on the intensity of the interoperability connection. There is a crucial role of enterprise architects handling such semantic synchronizations / transformations. 
Depending on the duration of the cooperation, the overlapping semantic areas will increase. When focal players communicate intensively with each other during the longer period, their ontology could coincide, which means that VO-s with longer history will have similar semantics, working principles, etc.

Analogically to the any organizational domain, three types of communication in EA governance can be identified - strategic, tactical and operational communication.

As usually, the strategic communication has most important influence on the company. It reinforces organizational message and brand, prevents contradictory and confusing messaging, allows creation and distribution of communication, that being different in style and purpose, has an inner coherence. Strategic communication conveys deliberate messages through the most appropriate media to the designated audiences at the appropriate time to contribute to and achieve the needed long-term effect.

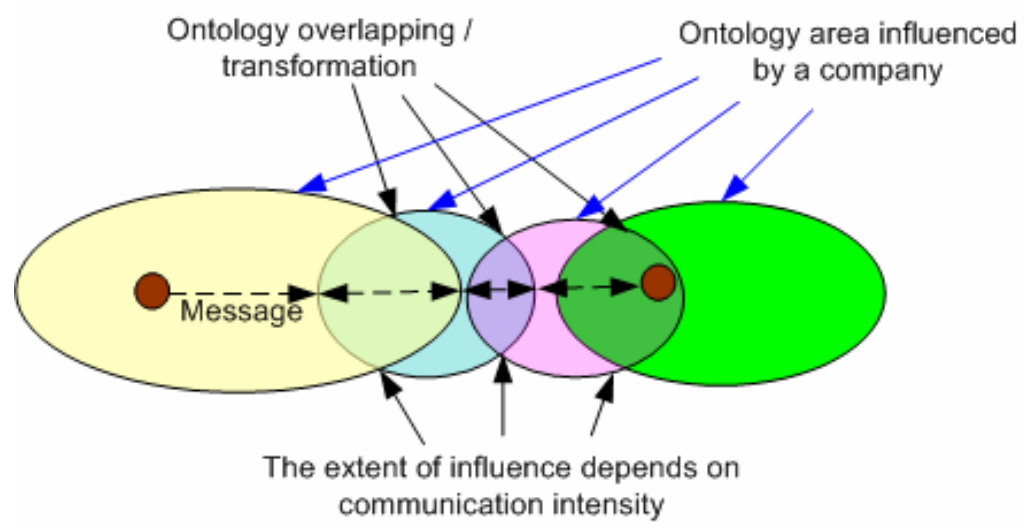

Fig. 4. Ontology transformation

The tactic communication is dealing with information that focuses from one responsible person to another certain person in tactical forces. The agreements made in this level of communication are for example Service Level Agreements, detailed business processes agreements, semantics managements, business environment monitoring. In brief, the mission of tactic communication is to provide business and technology solutions with smooth business cooperation between VOC-s and external partners, and to prepare disaster recovery scenarios and applications. The main challenges of tactic communication are to get data for operational situation management (including situation awareness), decision support, information fusion, situations control and situation prediction, semantic information processing (including semantic modeling), ontologies, knowledge representation and others.

Operational communications handles low-level topics, such as incidents, problems, change management, new developments, infrastructure management and support.

Thus, from VOC-s EA ontology harmonization point of view, the tactical communications have the highest importance, as the agreements made on that level have most significant influences to the VOC and thus also for VO (Fig. 5). 


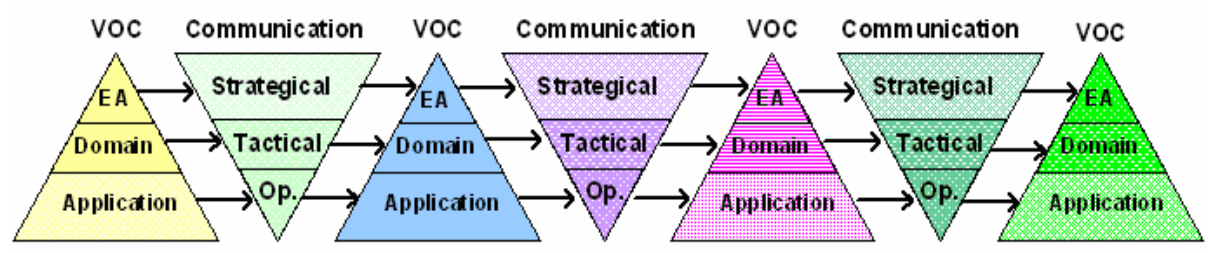

Fig. 5. Communication levels in ontology management

\section{EA Roles in VOC}

As above described, there are many EA frameworks available. As every architecture, according to our understanding, is context specific, it is possible to find out of the existing EA frameworks the most suitable one for an ordinary organization. The problem lies in the VO characteristic, as VO does not have a common ownership, which could force companies to operate in the same manner.

In context of VO, the EA's focus must be determined in more detail by the interoperability topics. Based on that, our research group is convinced, that the EA should be divided into three levels: EA level, Domain Level and Application level, where each of these levels will handle all five EA management layers (KPI-s, processes, data, application, infrastructure) in necessary level of generalization and in an easily communicable way.

Each of these levels should be covered by the EA architects. As EA as a discipline is quite novel (comparing e.g. with project management), then this is one of the reasons why different organizations use different titles to designate the Architect who leads the EA projects. The most commonly used are Chief Architect, Enterprise Architect, Chief IT Architect, IT/Enterprise Architecture Manager.

In addition to the Chief EA architect, there is a need for other roles in EA governance dealing with information, security, applications, infrastructure and business processes as well as with SOA (Service Oriented Architecture).

According our research group's approach, EA will be implemented through the six main EA roles:

1. Chief Architect - responsible for EA processes and EA team management;

2. Business Architect - responsible for business requirements, semantics and for consistent business processes management;

3. SOA architect - responsible for SOA governance, including service contracts;

4. Solution Architect - responsible for applications lifecycle management processes;

5. Data Architect - responsible for master data management processes and information management;

6. Infrastructure Architect - responsible for technical framework.

The discussions about the role Chief Security Architect constantly arises, yet in most cases security issues should be handled within pre-described roles. 
Depending on company size, these roles should be assigned in a way where a person performs one or several roles.

What we would like to emphasize is that these roles should differentiate for themselves EA communication layers (i.e. EA level, Domain level, application level) and prepare their messages and strategies in appropriate way to simplify cooperation between collaboration partners. When these levels are accurately managed, the ontology overlapping will be accelerated and collaboration intensity will be promoted.

\section{Conclusion}

Globalization and the economic transformation taking place in the world economy, bring new opportunities and challenges for the domestic SMEs. The form of VO will dominate in today's marketplace. SMEs' alliance models of operations promote business process innovation and allow SMEs to compete in new ways getting better reward for their work and gaining greater financial strength, which in turn will give them the financial capability to advance and develop their products and services.

At the same time, the form of VO will raise a lot of complexity, mostly caused by missing central management. As each company in VO will have its own goals, mission, strategy, processes and characteristics, different ICT technology platforms, applications and policies, as well as different principles for Enterprise Architecture management, it is a rather a challenge to manage effective collaboration between VOC-s and VO's external partners.

The current article analyses only one aspect of VO architecture management, which is the communication, which seams to be the most important aspect. By communication, it is possible to influence companies in VO to unify their ICT technical platforms and working principles, as there is a lack of central governance, which in ordinary organization may enforce implementation of unified standards.

To conclude, our working team is convinced that in VO the VO enterprise architecture cannot be directly controlled, the VO focal players can only influence it, having intensive communication with its partners. In EA management, the EA architects' roles should focus on proposed EA levels and build up their work on a way that each EA layer can be communicated separately as the granularity, messages and the information consumers are in various levels and have different expectations.

As the communication will take the crucial role in EA management in VO, the architects need to have an excellent social skills using as much as formal and informal communication to distribute their views in VO to establish more flexible EA solution, which will enable VO to use it characteristics - flexibility, dynamism, and its robustness.

Our further research will focus on communication issues and barriers that organizations, invited to participate in VO will have and we will concentrate on the question how to accelerate the new organization adaptation into VO. 


\section{References}

1. Kangilaski, T.: ICT and Business Alignment in Virtual Organization. In: 6th IEEE International Conference on Industrial Informatics (INDIN), pp. 1251-1256. IEEE Press, Daejon (2008)

2. Katzy, B.R.: Design and Implementation of Virtual Organizations (1998), http: //portal.cetim.org/file/1/67/Katzy-1998-Design-andImplementation-of-Virtual-Organizations.pdf

3. Virtual organizations: systems and practices. In: Camarinha-Matos, L.M., Afsarmanesh, H., Ollus, M. (eds.). Springer, New York (2005)

4. Camarinha-Matos, L.M.: Infrastructures for virtual organizations - where we are. In: IEEE Conference ETFA 2003, September 16-19, vol. 2, pp. 405-416. IEEE Press, Lisbon (2003)

5. Norton, B., Smith, C.: Understanding the virtual organization. Barron's Educational Series, Hauppauge (1997)

6. Davidov, W.H., Malone, M.S.: The virtual corporation. In: Structuring and Revitalizing the Corporation for the 21st Century. The Virtual Corporation, HarperBusiness (1992)

7. Ring, P.S., van de Ven, A.H.: Structuring cooperative relationships between organizations. Strategic Management Journal 13, 483-498 (1992)

8. Byrne, J.A., Brandt, R., Port, O.: The Virtual Corporation. Business Week 8, 36-40 (1993)

9. Kangilaski, T.: Virtual Organization and Supply Chain Management. In: 10th IEEE International Conference on Emerging Technologies and Factory Automation, ETFA 2005, Catania, Italy, September 19-22, pp. 705-712. IEEE Press, Los Alamitos (2005)

10. Wigand, R., Picot, A., Reichwald, R.: Information, organization and management: Expanding markets and corporate boundaries. Wiley, Chichester (1997)

11. Shao, Y.P., Liao, S.Y., Wang, H.Q.: A model of virtual organizations. Journal of Information Science 24(5), 305-312 (1998)

12. Manheim, M.L.: Cognitive Informatics: Theory and Implications for a People-Based Enterprise Information Architecture. In: Pacific Research Institute for Information Systems and Management Consortium PRIISM 1996 International Conference, pp. 341-353. Colorado Springs: University of Colorado at Colorado Springs (1996)

13. Holland, C.P., Lockett, A.G.: Business Trust and the Formation of Virtual Organizations. In: 31st Annual Hawaii International Conference on System Sciences, vol. VI, pp. 602 609. Computer Society Press, Kauai (1998)

14. Travica, B.: The Design of the Virtual Organization: A Research Model. In: Americas Conference on Information Systems,, AMCIS, Indianapolis, August 15-17, pp. 417-419 (1997)

15. Kangilaski, T.: Virtual Organization for Power Network Management. In: 2nd IEEE International Conference on Industrial Informatics, INDIN 2004, Berlin, Germany, June 24-26, pp. 169-174. IEEE, Berlin (2004)

16. Garvin, D.A.: The Processes of Organization and Management. Sloan Management Review 39(4), 33-50 (summer 1998)

17. Scott, W.R.: Organizations: Rational, Natural and Open Systems, 5th edn. Prentice Hall, Upper Saddle River (2003)

18. Quinn, B.: Intelligent enterprise: a knowledge and service based paradigm for industry. The Free Press, New York (1992)

19. Camarinha-Matos, L.M., Afsarmanesh, H.: Creation of Virtual Organizations in A breeding environment. In: 12th IFAC Symposium on Information Control Problems in Manufacturing, INCOM 2006, Industrial Engineering, Saint-Etienne, France, May 17-19, vol. 2, pp. 595-603 (2006) (preprints) 
20. Strader, T.J., Lin, F., Shaw, M.J.: Information structure for electronic virtual organization management. Decision Support Systems 23, 75-94 (1998)

21. Benabdelkader, A.: Information Integration among Heterogeneous and Autonomous Applications, Ph.D thesis. Amsterdam University (2002)

22. Gou, H., Huang, B., Liu, W., Li, X.: A framework for virtual enterprise operation management. In: Computers in Industry, vol. 50(3), pp. 333-352. Elsevier Science Publishers BV, Amsterdam (2003)

23. Maloneand, T.W., Crowston, K.: The Interdisciplinary Study of Coordination. ACM Computing Surveys 26(1), 87-119 (1994)

24. Kangilaski, T.: Interoperability Issues in Virtual Organization - How to Proceed? In: 12th IEEE Conference on Emerging Technologies and Factory Automation, ETFA 2007, September 25-28, pp. 1293-1299. IEEE Press, Patras (2007)

25. The Open Group: TOGAF ${ }^{\mathrm{TM}}$ Version 9 - The Open Group Architecture Framework, http: / /www. opengroup.org/architecture/togaf9-doc/arch/

26. Johnson, N.L.: Collective problem solving: Functionality beyond the Individual, Los Alamos National Laboratory, New Mexico (1998),

http://collectivescience.com/Documents_1/NLJsims_AB_v11.pdf 